\title{
Bilingualism and creativity: benefits in convergent thinking come with losses in divergent thinking
}

\author{
Bernhard Hommel ${ }^{1}$, Lorenza S. Colzato ${ }^{1}$, Rico Fischer ${ }^{2}$ and Ingrid K. Christoffels ${ }^{1}$ \\ 1 Institute for Psychological Research and Leiden Institute for Brain and Cognition, Leiden University, Leiden, Netherlands \\ ${ }^{2}$ Cognitive Psychology Unit, Technische Universität Dresden, Dresden, Germany
}

Edited by:

Teresa Bajo, Universidad de Granada

Spain

Reviewed by:

Julia Festman, Otto-von-Guericke University Magdeburg, Germany

Anatoliy Vladimirovich Kharkhurin

American University of Sharjah,

United Arab Emirates

*Correspondence:

Bernhard Hommel, Department of Psychology, Cognitive Psychology

Unit, Leiden University,

Wassenaarseweg 52, 2333 AK

Leiden, Netherlands.

e-mail: hommel@fsw.leidenuniv.nl
Bilingualism is commonly assumed to improve creativity but the mechanisms underlying creative acts, and the way these mechanisms are affected by bilingualism, are not very well understood. We hypothesize that learning to master multiple languages drives individuals toward a relatively focused cognitive-control state that exerts strong top-down impact on information processing and creates strong local competition for selection between cognitive codes. Considering the control requirements posed by creativity tasks tapping into convergent and divergent thinking, this predicts that high-proficient bilinguals should outperform low-proficient bilinguals in convergent thinking, while low-proficient bilinguals might be better in divergent thinking. Comparing low- and high-proficient bilinguals on convergent-thinking and divergent-thinking tasks indeed showed a high-proficient bilingual advantage for convergent thinking but a low-proficient bilingual advantage for fluency in divergent thinking. These findings suggest that bilingualism should not be related to "creativity" as a unitary concept but, rather, to the specific processes and mechanisms that underlie creativity.

Keywords: bilingualism, creativity, divergent thinking, convergent thinking

\section{INTRODUCTION}

Increasing evidence suggests that speaking more than one language does not only improve one's verbal skills but also more general, non-linguistic cognitive abilities. For instance, bilingual individuals have been demonstrated to outperform monolinguals in problem solving (Bain, 1975), perceptual focusing (Duncan and De Avila, 1979), and the Simon task (e.g., Bialystok et al., 2004; for a general review, see Bialystok and Craik, 2010). According to a growing consensus, the bilingual benefit is related to executive control functions, which are assumed to improve by learning multiple languages. To account for the bilingual benefit, some of the earlier approaches have considered that dealing with a new language might require the suppression of the dominant language, which might imply improvements in inhibitory control (Green, 1998; Bialystok, 2001). Other approaches have argued that preventing conflict between languages does not necessarily require direct inhibition but the combination of attentional top-down biasing together with local competition (i.e., direct interactions between alternative cognitive codes) may do (Poulisse and Bongaerts, 1994; Dijkstra and van Heuven, 1998; La Heij, 2005; Bialystok et al., 2006). This latter approach has received support from the observation that bilinguals are no more efficient in inhibiting unwanted responses than monolinguals but are less efficient than monolinguals in distributing attentional resources over multiple visual target events (Colzato et al., 2008). This suggests that learning multiple languages does not improve inhibitory skills but, rather, leads to a stronger, more selective focusing of cognitive control (Colzato et al., 2008).

The aim of the present study was to further characterize this focusing of control by investigating the impact of bilingualism on different types of creativity. Authors have argued at length about how the concept of creativity should be defined, whether creativity research should focus on the creative individual, the creative act, or the cognitive processes leading to it, and there is accordingly no consensus as to how creativity should be measured (for an overview, see Runco, 2007). Massive research from the last 40 years or so provides strong evidence that bilingualism somehow supports creativity, and a recent report of the European commission has listed more than 200 articles demonstrating this connection (European Commission, 2009). Unfortunately, however, the methodological diversity and sample characteristics of these studies are enormous, which renders it more than questionable whether they were actually assessing the same construct and processes. Moreover, there is still no mechanistic model explaining how creative processes operate and how bilingualism might affect these operations, which in view of the lack of conceptual clarity may not be surprising.

To address this issue, we tried to avoid addressing creativity as a whole. Instead, we compared high-proficient bilinguals with low-proficient bilinguals in two tasks that are likely to represent relatively process-pure measures of components of creativity: divergent thinking and convergent thinking. We do not claim that these are the only processes involved in creative acts (even though Guilford, 1967, considers them the by far most important) nor that individuals showing good performance with regard to these components need to be considered creative in general. Rather, we considered these two components and the two related assessments tasks as - in contrast to other components and tasks, and to creativity as a whole - the cognitive-control operations they are likely to rely on are relatively well understood (Hommel et al., manuscript 
submitted). Moreover, the fact that they are uncorrelated (Akbari Chermahini and Hommel, 2010) suggests that they are measuring different components of creativity indeed.

Divergent thinking can be defined as the process that allows people to generate as many responses as possible based on relatively weak constraints. As an example, in Guilford's (1967) alternate uses task (AUT) people are presented with a simple object, such as a pen, and asked to generate as many uses for that object they can think of. The results are commonly scored regarding the number of responses (fluency), the number of different categories being used (flexibility), the degree to which the responses differ from the standard or group mean (originality), and the amount of detail (elaboration). In contrast, convergent thinking can be defined as a more strongly constrained process that searches for one possible outcome. As an example, in Mednick's (1962) remote associates task (RAT) people are presented with three concepts, such as "hair," "stretch" and "time," and they are to identify the one concept that fits with all three in terms of association, meaning, or abstraction, such as "long" in the example.

Even though one can argue that both types of processes and tasks share a number of aspects, they are likely to require, or at least benefit from two different configurations of cognitive control. In its most elementary form, any type of biologically plausible decision-making can be considered a competition between alternative codes or representations (Bogacz, 2007) - such as between representations of the English word "frog" and the semantically equivalent Dutch word "kikker" in a picture-naming EnglishDutch bilingual, between representations of the alternative uses of a "pen" in the AUT, or between representations of close associates of the three defining words in a trial of the RAT. This kind of "local competition," as we will call it, is likely to generate random results unless it is steered by the current task goal. Duncan et al. (1996) have suggested that the impact of task goals on behavioral control might consist in providing top-down support for those representations that are most consistent with the current goal, so that the competition between cognitive representations can be considered a top-down "biased competition." As suggested by Colzato et al. (2008), people might differ with respect to the degree to which they experience local competition and/or the degree to which they bias this competition by top-down processes. Consider what possible differences regarding cognitive-control states (strong versus weak top-down bias and/or local competition) imply for different types of creativity tasks.

Divergent thinking (as assessed by the AUT) is likely to benefit from a cognitive-control state that provides a minimum of top-down bias and local competition, so that the individual can easily and quickly "jump" from one thought to the other in an only weakly guided fashion (Hommel et al., manuscript submitted). In contrast, convergent thinking (as assessed by the RAT) is likely to benefit from strong top-down bias (that is representing the greater number of constraints that possible solutions need to meet) and strong local competition (as only one solution can be right). If so, engaging in divergent thinking should facilitate subsequent performance in tasks that require weak, "distributed" control while engaging in convergent thinking should be beneficial for subsequent performance in tasks requiring a more focused, exclusive control style, that is, strong top-down control and local competition. Indeed, previous divergent thinking was found to improve performance in tasks that require the distribution of attention to two successive visual targets (Hommel et al., manuscript submitted) and increased inter-task interactions between two overlapping tasks (Fischer and Hommel, submitted), while previous convergent-thinking improved performance in selective-attention and response-competition tasks (Hommel et al., manuscript submitted).

Relating the findings from research on bilinguals to the observations from creativity studies suggests that the cognitive-control style that seems to be acquired by learning multiple languages fits well with the style implied by convergent thinking. If so, a straightforward hypothesis presents itself: high-proficient bilinguals should outperform low-proficient bilinguals in convergent thinking while the opposite should be the case with divergent thinking. At first sight, this hypothesis seems to be disproved by the available evidence. Numerous studies have claimed that bilingualism has a specific, positive effect on divergent thinking (for an overview, see Ricciardelli, 1992). However, previous studies have a number of characteristics that make it difficult to relate them to our hypothesis, such as reporting only aggregated total scores of creativity (across often heterogeneous scales) and the use of tasks that are unlikely to provide sufficiently process-pure measurements of convergent versus divergent thinking. For instance, the recent studies of Kharkhurin $(2009,2010)$ employed the abbreviated torrance test for adults (ATTA, Goff and Torrance, 2002) to assess divergent thinking. The test consisted of three activities: identifying the troubles that one may encounter when walking on air, completing incomplete pictures, and drawing as many pictures as possible based on a given group of triangles. Even though all these activities certainly require some form of creativity, they all seem to be much more balanced with respect to the generation aspect (that would benefit from weak top-down control and local competition) and the number of constraints (which call for strong top-down control and local competition) than the AUT (which has fewer constraints) on the one hand and the RAT (which allows for one result only) on the other. Hence, the ATTA arguably mixes divergent and convergent operations more than necessary, which makes it difficult to make predictions from a control-state point of view. Moreover, Ricciardelli (1992) already identified a number of studies that did not show the expected divergent-thinking benefits in bilinguals or even an advantage for monolinguals. More recently, two other studies reported better performance in monolinguals than bilinguals in a verbal fluency task (requiring to generate as many exemplars of a given category as possible) that bears some similarities to the divergent-thinking AUT (Rosselli et al., 2000; Gollan et al., 2002). Hence, a closer look reveals that the evidence for better divergent thinking in bilinguals is rather mixed (we consider some possible reasons in the Discussion), which is why we considered it still reasonable to compare high-proficient with lowproficient bilinguals in divergent thinking (assessed by means of the AUT) and convergent thinking (assessed by means of the RAT) separately.

\section{MATERIALS AND METHODS PARTICIPANTS}

Forty-two young healthy adults served as participants for partial fulfillment of course credit or a financial reward and constituted the two language groups: low-proficient and high-proficient 
Table 1 | Demographic data measures, vocabulary proficiency scores, originality, fluency, flexibility, and elaboration scores from the alternate uses task (AUT), the number of correct items from the remote associates task (RAT), means, and SD for the low-proficient and high-proficient bilinguals are shown.

\begin{tabular}{lll}
\hline Sample & Low-proficient & High-proficient \\
\hline$N$ (F:M) & $12: 9$ & $12: 9$ \\
Age (in years) & $19.6(3.2)$ & $20.7(1.1)$ \\
IQ & $121.8(4.1)$ & $123.7(6.0)$ \\
English vocabulary score* & $3754(748)$ & $4164(520)$ \\
AUT & & \\
$\quad$ Elaboration & $4.2(3.1)$ & $3.3(2.3)$ \\
$\quad$ Fluency* & $40.7(11.6)$ & $32.5(11.1)$ \\
$\quad$ Flexibility & $27.2(7.5)$ & $26.4(8.3)$ \\
$\quad$ Originality & $17.4(16.1)$ & $12.8(6.7)$ \\
RAT* & $13.3(3.1)$ & $15.8(4.2)$ \\
\hline
\end{tabular}

${ }^{*} p<0.05$ (significant group difference).

bilinguals. All reported having normal or corrected-to-normal vision, and were not familiar with the purpose of the experiment. Half of the participants were low-proficient bilingual German native-speaker students of the Technische Universität Dresden (Germany), and the other half were Dutch-English high-proficient bilinguals living in the Netherlands. All participants were tested by the same instructional protocols, although the actual testing was carried out in two different countries. The high-proficient bilingual participants attended the high school in English and some of them had lived part of their life in an English-speaking country. They used both Dutch and English on a daily basis throughout their lives. As research with bilingual adults (Kroll and Stewart, 1994) and children (Bialystok, 1988) has revealed that the cognitive and linguistic consequences of bilingualism are more salient for those bilinguals who are relatively balanced in their proficiency, we only considered balanced bilinguals for the present study. The low-proficient bilingual German participants were not functionally fluent in any other language despite the inevitable language courses in school. All participants in both groups attended university and shared similar middle-class socioeconomic backgrounds, and they were matched for age, sex, and IQ (measured by Raven's standard progressive matrices, SPM), see Table 1. Participants gave their written informed consent prior to their inclusion in the study in accordance to the 1964 Declaration of Helsinki.

\section{PROCEDURE AND DESIGN}

The experiment consisted of a 45-min session in which participants completed the AUT to assess divergent thinking, the RAT to assess convergent thinking, a vocabulary test to access participants' proficiency in English, and a short-version of a reasoningbased intelligence test (Raven's SPM; Raven et al., 1988). After completion of the tasks, the participants were debriefed and paid.

\section{AUT (divergent thinking)}

In this task (based on Guilford, 1967, and translated into Dutch and German), participants were asked to list as many possible uses for three common household items (brick, shoe, and newspaper) as they can within $10 \mathrm{~min}$. Scoring comprised of four components:
Originality: Each response is compared to the total amount of responses from all of the subjects. Responses that were given by only $5 \%$ of the group count as unusual ( 1 point) and responses given by only $1 \%$ of them count as unique ( 2 points).

Fluency: The total of all responses.

Flexibility: The number of different categories used.

Elaboration: The amount of detail (e.g. "a doorstop" counts 0, whereas "a door stop to prevent a door slamming shut in a strong wind" counts 2 (1 point for explanation of door slamming and another for further detail about the wind).

\section{RAT (convergent thinking)}

In this task (based on Mednick, 1962, and translated into Dutch and German), participants were presented with three unrelated words (such as time, hair, and stretch) and asked to find a common associate (long). Our version comprised of 30 items, which were to be worked through within $10 \mathrm{~min}$.

\section{English vocabulary test}

Participants' proficiency in English was assessed with a vocabulary test consisting of a non-speeded lexical decision task (Christoffels et al., 2006, manuscript submitted). The test consisted of words selected from five different word frequency bins and non-words. Participants were required to indicate whether or not they knew the meaning of the English letter strings. The score of the test ranges from 0 to 5,000 and is corrected for misattribution of non-words.

\section{SPM (intelligence test)}

The SPM assesses the individual's ability to create perceptual relations and to reason by analogy independent of language and formal schooling; it is a standard, widely used test to measure Spearman's $g$ factor and of fluid intelligence in particular.

\section{STATISTICAL ANALYSIS}

Independent $t$-tests were performed to test differences between the two groups. From the two tasks, five measures were extracted for each participant: originality, fluency, flexibility, and elaboration scores from the AUT, the number of correct items from the RAT. The measures were scored by two independent readers (Cronbach's alpha $=0.90)$. A significance level of $p<0.05$ was adopted for all tests.

\section{RESULTS}

No significant group differences were obtained for age, $t(40)=1.47, p=0.15$, and intelligence, $t(40)=1.17, p=0.25$. As expected, high-proficient bilinguals were significantly more proficient in the English vocabulary test than low-proficient bilinguals, $t(40)=2.06, p<0.05$, see Table 1 .

Performance in the RAT and AUT was good and comparable to performance in other studies (e.g., Akbari Chermahini and Hommel, 2010). As expected, high-proficient bilinguals showed better performance in the RAT task than low-proficient bilinguals, $t(40)=2.22, p<0.05$. Also as expected, all four scores of the AUT showed an advantage for low-proficient over high-proficient bilinguals. While this advantage did not reach significance for flexibility, $t(40)<1$, originality, $t(40)=1.19, p=0.24$, and elaboration, $t(40)=1.10, p=0.28$, it was reliable for fluency, $t(40)=2.31$, $p<0.05$, see Table 1 . 


\section{DISCUSSION}

The guiding hypothesis of this study assumes that speaking multiple languages leads to the adoption of a relatively focused cognitive-control state, at least as a default, which is characterized by a strong top-down biasing of information processing and strong local competition for selection between cognitive codes. Considering that this control-state fits with the control requirements of convergent thinking but not of divergent thinking, we predicted that high-proficient bilinguals should outperform low-proficient bilinguals in convergent thinking, whereas low-proficient bilinguals should perform better in divergent thinking. And this is exactly what the data show: high-proficient bilinguals excel in convergent thinking while low-proficient bilinguals excel in divergent thinking, at least with regard to the fluency score.

On the one hand, this outcome is consistent with previous observations that monolinguals outperform bilinguals in verbal fluency tasks (Rosselli et al., 2000; Gollan et al., 2002). On the other hand, however, it does not seem to fit with the general expectation that bilingualism is associated with greater cognitive flexibility and numerous studies that seem to support this expectation (cf., Ricciardelli, 1992; European Commission, 2009). One possible interpretation, which has been suggested by Kharkhurin (2010), is that verbal and non-verbal creativity tasks assess different skills and might be differently affected by bilingualism. Kharkhurin's specific suggestion is that bilinguals might excel in the non-verbal domain but be outperformed by monolinguals if it comes to verbal domains. However, not only is this suggestion difficult to combine with the fact that bilinguals must master language-related skills that monolinguals do not need to master, which again implies that bilinguals do have some unique expertise that relates to the verbal domain. It is also refuted by our findings. Both of our thinking tasks were clearly verbal and drawing on verbal skills, so that the better performance of bilinguals in the convergent-thinking task does not fit with the claim that bilinguals' performance is necessarily inferior to that of monolinguals. But, on the other hand, it is true that we demonstrated the predicted double dissociation for the verbal domain only, and it may very well be that non-verbal tasks show a different pattern.

Another aspect that might explain at least some inconsistencies in the field in general and with regard to the present findings in particular relates to the age of the investigated participants. The majority of studies on the relationship between bilingualism and creativity have focused on children (Kharkhurin, 2010). In line with earlier speculations (e.g., Eysenck, 1993; Ashby et al., 1999), there is increasing evidence for a reliable connection between dopamine and creativity performance, which for instance has been shown to vary with the individual density of dopamine receptors (de Manzano et al., 2010), genetic variability associated with striatal dopamine production (Reuter et al., 2006), and the Parkinson-related loss of dopaminergic neurons in the striatal pathway (Batir et al., 2009). Using the same tasks used in the present study, it could be demonstrated in healthy subjects that convergent and divergent thinking are mediated by both the individual tonic dopamine level (Akbari Chermahini and Hommel, 2010) and phasic changes of this level (Akbari Chermahini and Hommel, submitted). Interestingly, the brain systems that are targeted by the two major dopaminergic pathways in humans (the frontal and the striatal pathway; see Cools, 2008) are particularly strongly affected by developmental factors and are suspected to keep developing into early adulthood (Gogtay et al., 2004). This fits with observations of considerable variability of individual creativity measures over the lifespan (e.g., Simonton, 1997; Wohl, 2003). Hence, it remains to be seen whether observations from children really generalize to adults, and whether individual differences in creativity tasks are stable over time.

Finally, we would like to emphasize that we do not consider our measures of performance in divergent and convergent-thinking tasks to represent creativity as a whole - be it as a state or a personal trait. Divergent and convergent thinking are likely to be very important, if not crucial (Guilford, 1967), for many creative acts, but such acts can be suspected to comprise of a whole sequence of processes and components. Many authors since Wallas (1926) have assumed that creative acts run through at least four stages including preparation, which involves investigating the problem; incubation, which involves (often unconscious) thinking about the problem; illumination, where ideas come together to form a possible solution; and verification, which involves evaluating the chosen option. It makes sense to characterize the first two stages as emphasizing divergent processes and the final two stages as emphasizing convergent processes (Hommel, in press), and it may very well be that individual performance therein can be predicted to some degree based on the measures used in the present study. Nevertheless, the complexity of the respective stages strongly suggests that a number of other cognitive operations are involved. Accordingly, it would be far-fetched to consider good performance in the AUT and the RAT sufficient to categorize individuals as "creative." Indeed, we sincerely believe that unpacking complex concepts like "creativity" into their component processes represents a crucial step in constructing mechanistic models that are sufficiently transparent to undergo rigorous empirical testing.

And the same goes for the cognitive benefits that come along with bilingualism: modeling them in detail will also require the unpacking into component processes. The present findings suggest that one of these component processes is responsible for the regulation of cognitive-control states. If we assume that one dimension on which these states vary relates to the degree of top-down biasing of information processing and of local competition between alternative cognitive codes (Colzato et al., 2008; Hommel et al., manuscript submitted), having learned to handle multiple tasks seems to drive individuals toward the pole of the dimension that represents more biasing and more competition. Accordingly, bilinguals are likely to show particularly good performance on tasks that are relying or benefiting from this control state but to show relatively poor performance on tasks that require or benefit from weaker top-down control and less local competition. Examples for the former are tasks inducing response conflict (Bialystok et al., 2004) and convergent thinking, while examples for the latter are tasks that call for the distribution of attention (Colzato et al., 2008) and divergent thinking.

\section{ACKNOWLEDGMENTS}

The research of Lorenza S. Colzato is supported by NWO (Netherlands Organization for Scientific Research). 


\section{REFERENCES}

Akbari Chermahini, S., and Hommel, B. (2010). The (b)link between creativity and dopamine: spontaneous eye blink rates predict and dissociate divergent and convergent thinking. Cognition 115, 458-465.

Ashby, F. G., Isen, A. M., and Turken, A. U. (1999). A neuro-psychological theory of positive affect and its influence on cognition. Psychol. Rev. 106, 529-550.

Bain, B. (1975). Toward an integration of Piaget and Vygotsky: bilingual considerations. Linguistics 16, 5-20.

Batir, A., Lhommee, E., Ardouin, C., Fraix, V., Seigneuret, E., Chabardes, S., Benabid, A.-L., Pollak, P., and Krack, P. (2009). Creativity induced by dopamine agonists in Parkinson's disease. Mov. Disord. 24, 234.

Bialystok, E. (1988). Levels of bilingualism and levels of linguistic awareness. Dev. Psychol. 24, 560-567.

Bialystok, E. (2001). Bilingualism in Development: Language, Literacy, and Cognition. Cambridge: Cambridge University Press.

Bialystok, E., and Craik, F. I. M. (2010). Cognitive and linguistic processing in the bilingual mind. Curr. Dir. Psychol. Sci. 19, 19-23.

Bialystok, E., Craik, F. I. M., Klein, R., and Viswanathan, M. (2004). Bilingualism, aging, and cognitive control: evidence from the Simon task. Psychol. Aging 19, 290-303.

Bialystok, E., Craik, F. I. M., and Ryan, J. (2006). Executive control in a modified anti-saccade task: effects on aging and bilingualism. $J$. Exp. Psychol. Learn. Mem. Cogn. 32, 1341-1354.

Bogacz, R. (2007). Optimal decisionmaking theories: linking neurobiology with behavior. Trends Cogn. Sci. (Regul. Ed.) 11, 118-125.

Christoffels, I. K., de Groot, A. M. B., and Kroll, J. F. (2006). Memory and language skills in simultaneous interpreting: expertise and language proficiency. J. Mem. Lang. 54, 324-345.

Colzato, L. S., Bajo, M. T., van den Wildenberg, W., Paolieri, D., Nieuwenhuis, S. T., La Heij, W., and Hommel, B. (2008). How does bilingualism improve executive control?
A comparison of active and reactive inhibition mechanisms. J. Exp. Psychol. Learn. Mem. Cogn. 34, 302-312.

Cools, R. (2008). Role of dopamine in the motivational and cognitive control of behaviour. Neuroscientist 14, 381-395.

de Manzano, O., Cervenka, S., Karabanov, A., Farde, L., and Ullén, F. (2010). Thinking outside a less intact box: thalamic dopamine D2 receptor densities are negatively related to psychometric creativity in healthy individuals. PLOS ONE 5, e10670. doi:10.1371/journal.pone. 0010670

Dijkstra, T., and van Heuven, W. J. B. (1998). "The BIA model and bilingual word recognition," in Localist Connectionist Approaches to Human Cognition, eds J. Grainger and A. Jacobs (Hillsdale, NJ: Erlbaum), 189-225.

Duncan, J., Emslie, H., Williams, P., Johnson, R., and Freer, C. (1996). Intelligence and the frontal lobe: the organization of goaldirected behavior. Cogn. Psychol. 30, 257-303.

Duncan, S. E., and De Avila, E. (1979). Bilingualism and cognition: some recent findings. NABE J. 4, 15-50.

European Commission. (2009). Study on the Contribution of Multilingualism to Creativity: Final Report. Available at: http://eacea.ec. europa.eu/llp/studies/study_on_the contribution_of_multilingualism_ tt_creativity_en.php

Eysenck, H. J. (1993). Creativity and personality: suggestions for a theory. Psychol. Inq. 4, 147-178.

Goff, K., and Torrance, E. P. (2002). Abbreviated Torrance Test for Adults. Bensenville, IL: Scholastic Testing Service.

Gogtay, N., Giedd, J. N., Lusk, L., Hayashi, K. M., Greenstein, D., Vaituzis, A. C., Nugent, T. F., Herman, D. H., Clasen, L. S., Toga, A. W., Rapoport, J. L., and Thompson, P. M. (2004). Dynamic mapping of human cortical development during childhood through early adulthood. Proc. Natl. Acad. Sci. U.S.A. 101, 8174-8179.
Gollan, T. H., Montoya, R. I., and Werner, G. A. (2002). Semantic and letter fluency in SpanishEnglish bilinguals. Neuropsychology 16, 562-576.

Green, D. W. (1998). Mental control of the bilingual lexico-sematic system. Biling. (Camb. Engl.) 1, 67-81.

Guilford, J. P. (1967). The Nature of Human Intelligence. New York: McGraw-Hill.

Hommel, B. (in press). "Convergent and divergent operations in cognitive search," in Cognitive search: Evolution, Algorithms, and the Brain. Strüngmann Forum Reports, Vol. 9 , eds P. M. Todd, T. T. Hills, and T. W. Robbins (Cambridge, MA: MIT Press).

Kharkhurin, A. V. (2009). The role of bilingualism in creative performance on divergent thinking and invented alien creatures tests. J. Creat. Behav. 43, 59-71.

Kharkhurin, A. V. (2010). Bilingual verbal and nonverbal creative behavior. Int. J. Biling. 14, 211-226.

Kroll, J. F., and Stewart, E. (1994). Category interference in translation and picture naming: evidence for asymmetric connections between bilingual memory representations. J. Mem. Lang. 33, 149-174.

La Heij, W. (2005). "Lexical selection in monolinguals and bilinguals," in Handbook of Bilingualism, eds J. F. Kroll and A. M. B. de Groot (New York: Oxford University Press), 289-307.

Mednick, S. (1962). The associative basis of creative problem solving process. Psychol. Rev. 69 200-232.

Poulisse, N., and Bongaerts, T. (1994). First language use in second language production. Appl. Linguist. 15, 36-57.

Raven, J. C., Court, J. H., and Raven, J. (1988). Manual for Raven's Progressive Matrices and Vocabulary Scales. London: Lewis.

Reuter, M., Roth, S., Holve, K., and Hennig, J. (2006). Identification of first candidate genes for creativity: a pilot study. Brain Res. 1069, 190-197.
Ricciardelli, L. A. (1992). Creativity and bilingualism. J. Creat. Behav. 26, 242-254.

Rosselli, M., Ardila, A., Araujo, K. Weekes, V. A., Caracciolo, V., Padilla, M., and Ostrosky-Solís, F. (2000). Verbal fluency and repetition skills in healthy older Spanish-English bilinguals. Appl. Neuropsychol. 7, 17-24.

Runco, M. A. (2007). Creativity. Theories and Themes: Research, Development, and Practice. San Diego, CA: Academic Press.

Simonton, D. K. (1997). Creative productivity: a predictive and explanatory model of career trajectories and landmarks. Psychol. Rev. 104, 66-89.

Wallas, G. (1926). The Art of Thought. New York: Harcourt Brace.

Wohl, E. (2003). Creativity and Affective Traits Across the Lifespan: Developmental Influences Among Adolescents and Older Adults. Ann Arbor, MI: UMI/ ProQuest.

Conflict of Interest Statement: The authors declare that the research was conducted in the absence of any commercial or financial relationships that could be construed as a potential conflict of interest.

Received: 03 May 2011; accepted: 29 September 2011; published online: 10 November 2011.

Citation: Hommel B, Colzato LS, Fischer $R$ and Christoffels IK (2011) Bilingualism and creativity: benefits in convergent thinking come with losses in divergent thinking. Front. Psychology 2:273. doi: 10.3389/fpsyg.2011.00273

This article was submitted to Frontiers in Cognition, a specialty of Frontiers in Psychology.

Copyright (C) 2011 Hommel, Colzato, Fischer and Christoffels. This is an openaccess article subject to a non-exclusive license between the authors and Frontiers Media SA, which permits use, distribution and reproduction in other forums, provided the original authors and source are credited and other Frontiers conditions are complied with. 